\title{
Effect of ovarian cystic or haemorrhagic follicles on embryo recovery and survival after transfer in hCG-ovulated rabbits
}

\author{
F García-Ximénez, JS Vicente \\ Universidad Politécnica de Valencia, Departamento de Ciencia Animal, \\ Camino de Vera, 14, 46071 Valencia, Spain
}

(Received 1 July 1991; accepted 17 February 1992)

\begin{abstract}
Summary - The relationship between the presence of cystic and/or haemorrhagic follicles in both donor and recipient does and survival at birth of frozen-thawed embryos (778 embryos transferred) from 3 selected rabbit strains (NZ: New Zealand white; SY and SB: synthetic breeds) were studied. Donor does (SY:108; NZ:99; SB:96) were mated and treated with 25 IU of hCG. Only morphologically normal oviductal morulae $(64-66 \mathrm{~h}$ ) were frozen. Frozen-thawed embryos from each of the 90 donor does were transferred into the oviducts of synchronized recipient does of the same strain $48 \mathrm{~h}$ after injection of $25 \mathrm{IU}$ of hCG (SY:31; NZ:28; SB:31). The frequency of follicular anomalies (36 and $43 \%$ ) was high in both donor and recipient does, respectively, and it was not affected by strain or parity. The follicular anomalies had a negative effect on the percentage of embryos recovered in the oviduct $(70 \mathrm{vs} 77 \%$ ) but not on the percentage of recovered embryos catalogued as morphologically normal $(97 \%)$. The absence of follicular anomalies in recipient does had a significantly favourable effect on the pregnancy rate (63 vs 18\%; $P<0.05$ ) and consequently on embryo survival rate at birth (26 vs $7 \% ; P<0.01$ ).
\end{abstract}

cystic follicles / haemorrhagic follicles / embryo recovery / embryo transfer / rabbit

Résumé - Effets de la présence de follicules kystiques ou hémorragiques sur le taux de récupération d'embryons et de survie à la naissance après transfert chez des lapines traitées par hCG. La relation entre la présence de follicules kystiques et/ou hémorragiques chez des lapines donneuses et receveuses et la viabilité à la naissance d'embryons congelés-décongelés (nombre d'embryons transférés : 778) a été étudiée dans trois souches (NZ : néozélandaise, SY et SB : souches synthétiques). Les lapines donneuses (SY : 108, NZ:99, SB : 96) ont été traitées avec 25 UI d'hCG et saillies. Seules les embryons au stade morula morphologiquement normaux présents dans l'oviducte 64-66 heures après l'accouplement ont été congelés. Les embryons de 90 donneuses ont été transférés dans l'oviducte de receveuses de la même souche (qui avaient été synchronisées $48 \mathrm{~h}$ avant par injection de $25 \mathrm{Ul}$ d'hCG). La fréquence des anomalies folliculaires était élevée chez les donneuses (36\%) et les receveuses (43\%). II n'y avait pas de différences significatives entre souches ni entre nullipares et multipares. La présence de follicules anormaux sur l'ovaire avait un effet significativement négatif sur le taux de récupération dans l'oviducte (70\% vs $77 \%$ ). On n'a pas observé d'effet sur le pourcentage d'embryons morphologiquement normaux récupérés 
(97\%). La présence d'anomalies folliculaires chez les receveuses avait un effet significativement défavorable sur le taux de gestation (63\% vs $18 \%, \mathrm{P}<0,05)$ et par conséquent sur le taux de survie des embryons (26\% vs $7 \%, \mathrm{P}<0,01)$.

follicules kystiques / follicules hémorragiques / récupération d'embryons / transfer d'embryons / lapin

\section{INTRODUCTION}

Frequently in rabbit embryo cryopreservation procedures, ovulation is reinforced or induced in donor and recipient does with hCG treatment. However, this treatment may induce follicular anomalies such as cystic and haemorrhagic follicles. The frequency of these follicular anomalies varies with the hCG dose (Bomsel-Helmreich et al, 1989). Moreover, rabbit strains differ regarding hCG sensitivity (Hulot et al, 1988).

Using 3 rabbit strains, we examined the effects of the presence of follicular anomalies in donor and recipient does on the recovery rate and viability of transferred embryos.

\section{MATERIAL AND METHODS}

Sexually mature rabbit does from 3 strains were used (NZ: New Zealand White; SY and SB: synthetic breeds). Two (NZ and SY) were selected on litter size at weaning. The third (SB) was selected on growth rate from weaning to slaughter (28-70 days of age).

All the does were kept individually under the same environmental conditions ( $16 \mathrm{~h}$ light: $8 \mathrm{~h}$ dark, $20-25{ }^{\circ} \mathrm{C}$ ). Both nulliparous (182) and multiparous (121) donor does (SY:108; NZ:99; SB:96) were mated with fertile bucks of the same strain and immediately injected intravenously with $25 \mathrm{IU}$ of hCG (Coriogan, Ovejero) in the marginal ear vein. The morulae were recovered post-mortem 64-66 h post-coitum by perfusing the oviducts with $6 \mathrm{ml}$ of Dulbecco's phosphate-buffered saline (PBS; Sigma) containing $50 \%$ heat-inactivated rabbit serum (PBS1). This procedure allowed complete recovery of the oviductal contents (Adams, 1982).
The following parameters were recorded in donor does:

- induction of ovulation assessed by the presence (1) or absence (0) of luteinized follicles (forming corpora lutea) with ovulation stigmas;

- ovulation rate estimated as the number of luteinized follicles with ovulation stigmas counted under the dissecting microscope;

- follicular anomalies: presence (1) or absence $(0)$ of abnormal follicles (cystic and/or haemorrhagic). Follicles without ovulation stigmas and larger than ovulated follicles were considered as cystic or haemorrhagic, depending on the absence or presence of blood in the antral cavity;

- total number of embryos recovered;

- number of normal embryos according to morphological criteria (Carney and Foote, 1990).

Only normal morulae were frozen using the procedure derived from Tsunoda et al (1982) and Kojima et al (1985) and described by Garcia-Ximénez and Vicente (1991).

Transferable embryos from 90 donor does were used. The embryos of each donor doe were transferred to one recipient doe of the same strain. No transfer was carried out when the number of embryos by donor doe was less than 6. A total of 90 nulliparous females (SY:31; NZ:28; SB:31) were used as recipients. Only those with red or pink vulvar lips were injected intravenously with $25 \mathrm{IU}$ of hCG $48 \mathrm{~h}$ before oviductal transfer of the frozen-thawed embryos.

Surgical transfer was carried out by ventral midline laparotomy under a general anaesthesia (5/1 ketamine chlorhydrate/prometazine solution). The embryos suspended in PBS were held in a glass tube (1 $\mathrm{mm}$ external diameter and $0.5 \mathrm{~mm}$ internal diameter) connected to a $1-\mathrm{ml}$ insulin syringe with pressure tubing. The glass tube was inserted through the infundibulum $(0.5 \mathrm{~cm})$ into the oviduct and the embryos carefully placed. 
The following parameters were recorded at transfer or at the expected time of birth:

- induction of ovulation in recipient does;

- presence or absence of abnormal follicles according to the same criteria used for the donor does;

- full-term gestation or not (pregnancy rate);

- number of live pups per litter at birth;

- survival rate at birth: number of live pups/ number of embryos transferred.

The ovulation rate in recipient does was not estimated at the time of transfer since the excessive ovarian manipulation required to count all corpora lutea could increase the risk of oviductal adherences, thus altering transfer results.

Analysis of variance was used to evaluate the effects of strain, parity and follicular anomalies and their interactions on the ovulation rate, number of embryos recovered and the percentage of normal embryos. The number of recovered embryos was also analyzed by a variance-covariance analysis including the ovulation rate as a covariate. The mean values presented in the text were not obtained by the least-squares method.

The frequency of follicular anomalies and pregnancy rate was analyzed by a Chi-square. Chi-square significance with the Yates correction was used when only 2 cells were compared. Analysis of variance, after arcsin transformation of the survival rate at birth, was used to evaluate the effects of the factors (strain, follicular anomalies in recipient does and in donor does) and their interactions.

\section{RESULTS}

\section{Follicular anomalies in donor and recipient does. Effects of strain and parity}

All donor and recipient does ovulated. No significant differences between them as to frequency of follicular anomalies were detected (overall mean: $37.4 \%$ ). The frequency of the anomalies was not significantly affected in donor does by strain or parity or in recipient does by strain.

\section{Effects of strain, parity and follicular anomalies on ovulation rate and recovered embryos}

The ovulation rate of donor does was not significantly affected by the presence of follicular anomalies. Significant differences $(P<0.01)$ in ovulation rate were observed among the strains (SY:12.7 \pm 0.2 and $\mathrm{NZ}: 12.8 \pm 0.3$ vs SB $13.8 \pm 0.3$ ) and between nulliparous and multiparous does (12.3 \pm 0.2 vs $14.3 \pm 0.2, P<0.01)$. No interaction between strain and parity was seen. The lowest ovulation rate observed in donor does was 6 corpora lutea.

The number of recovered embryos analyzed at constant ovulation rate (regression coefficient of the covariate ovulation rate: $0.67, P<0.05$ ) was not different either among strains or between nulliparous and multiparous does $(9.7 \pm 0.2)$. The presence of follicular anomalies had a negative effect $(9.2 \pm 0.4$ vs $9.9 \pm 0.3, P<0.05)$. The percentage of recovered embryos with respect to ovulation rate was 77 in donor does without follicular anomalies, while in those with follicular anomalies this percentage was $70(P<0.05)$. The overall embryo recovery rate was $74 \%$.

The frequency of morphologically normal embryos was not significantly affected by follicular anomalies or by strain and parity (nulliparous and multiparous does). The overall percentage of normal embryos recovered was 97 .

\section{Effects of strain and follicular anomalies on the survival of frozen-thawed morulae}

\section{Embryo survival in all transfers}

No statistically significant differences in survival rate at birth were observed either 
between embryos from donor does, with or without follicular anomalies (12 and $22 \%$, respectively; table I) or among strains (SY: $24 \pm 4$; NZ: $12 \pm 4$; SB: $18 \pm 4$ ). However, the recipient does without follicular anomalies showed a higher survival rate at birth than the recipient animals with the anomalies ( 26 vs $7 \%$ respectively). No statistically significant interactions were observed between the factors.
The effects of follicular anomalies in donor and in recipient does on pregnancy rate, analyzed separately in each strain, were not statistically significant. No significant effect of strain was detected on pregnancy rate.

In all transfers (table II), follicular anomalies in recipient does had a negative effect on the pregnancy rate at birth of transferred does $(P<0.05)$, while the effect of

Table I. Effects of follicular anomalies in donor and recipient does on the embryonic survival rate at birth.

\begin{tabular}{|c|c|c|c|c|c|c|c|c|c|}
\hline \multirow[t]{3}{*}{ Donor does } & \multicolumn{6}{|c|}{ Recipient does } & \multirow{2}{*}{\multicolumn{3}{|c|}{ Total }} \\
\hline & \multicolumn{3}{|c|}{ Without anomalies } & \multicolumn{3}{|c|}{ With anomalies } & & & \\
\hline & No & $T E$ & $S R B$ & No & $T E$ & SRB & No & $T E$ & $S R B$ \\
\hline Without anomalies & 36 & $8.4 \pm 0.4$ & $32 \pm 4$ & 23 & $8.7 \pm 0.4$ & $6 \pm 3$ & 59 & $8.6 \pm 0.3$ & $22 \pm 3$ \\
\hline With anomalies & 16 & $9.2 \pm 0.5$ & $14 \pm 5$ & 15 & $8.4 \pm 0.4$ & $9 \pm 5$ & 31 & $8.8 \pm 0.3$ & $12 \pm 4$ \\
\hline Total & 52 & $8.7 \pm 0.3$ & $26 \pm 3^{a}$ & 38 & $8.6 \pm 0.3$ & $7 \pm 3^{b}$ & 90 & $8.6 \pm 0.2$ & $18 \pm 2$ \\
\hline
\end{tabular}

No $=$ number of does. $T E=$ mean of transferred embryos: means $\pm S E M$. SRB $=$ mean values of survival rate at birth (100 $\times$ No of live born/number of transferred): means \pm SEM. a,b Values with different superscripts are statistically different $(P<0.01)$.

Table II. Effects of follicular anomalies in donor and recipient does on the pregnancy rate evaluated at birth*.

\begin{tabular}{|c|c|c|c|c|c|c|}
\hline \multirow[t]{3}{*}{ Donor does } & \multicolumn{4}{|c|}{ Recipient does } & \multirow{2}{*}{\multicolumn{2}{|c|}{ Total }} \\
\hline & \multicolumn{2}{|c|}{ Without anomalies } & \multicolumn{2}{|c|}{ With anomalies } & & \\
\hline & No & $P R$ & No & $P R$ & No & $P R$ \\
\hline Without anomalies & 36 & $74^{a}$ & 23 & $17^{b}$ & 59 & 52 \\
\hline With anomalies & 16 & $38^{b}$ & 15 & $19^{b}$ & 31 & 28 \\
\hline Total & 52 & $63^{v}$ & 38 & $18^{w}$ & 90 & 43 \\
\hline
\end{tabular}

No: number of does; PR (pregnancy rate): $100 \times$ No of births/No of transferred recipient does; ${ }^{a, b}$ values with different superscripts are statistically different $(P<0.05){ }^{v, w}$ values in the total with different superscripts are statistically different $(P<0.05)$. 
these anomalies in donor does did not reach statistical significance. The anomalies in the donors had a significantly unfavourable effect on the pregnancy rate of the corresponding recipients does only when the latter had no ovarian anumalies (74 vs 38\%; $P<0.05$ ). This effect was less important than that of recipients (table II).

\section{Embryo survival at full-term pregnancy}

Out of a total of 90 transferred does, 39 $(43 \%)$ became pregnant and gave birth. No significant effects were found in the proportion of live pups at birth in relation to strain, follicular anomalies in donors or follicular anomalies in recipients. The embryo survival rate at birth in these 39 transfers was $43 \%$ (138 liveborn $/ 319$ transferred embryos).

\section{DISCUSSION}

In all 3 strains efficiency of ovulation treatment was demonstrated whether the does were simultaneously mated (donors) or not (recipients) with a buck. The hCG dose used in this work had been previously determined as optimal by other authors studying different rabbit breeds and strains (Bonhoff and Adams, 1985; Hulot et al, 1988).

The high frequency (donors: $36 \%$, recipients: $43 \%$ ) of observed follicular anomalies (cystic and haemorrhagic follicles) was in agreement with the results of BomselHelmreich et al (1989). These authors observed that rabbit doe follicles show cystic transformation (enlargement of the follicle) or even become partially haemorrhagic with hCG doses higher than $20 \mathrm{IU}$. These events were more frequent when higher hCG doses were used. The same authors suggested that occurrence of both follicular anomalies may depend on an excessive dose in the LH/hCG surge which generates follicular hyperstimulation of immature antral follicles. Some of these follicles may not have received enough hCG to ovulate and therefore start an ageing process which leads either to cysts or to haemorrhagic follicles; this is related to the degree of breakage of the different follicular layers.

Cystic or haemorrhagic follicles were also observed in relation to PMSG (50 IU) superovulatory treatment in rabbits (Garcia-Ximénez and Vicente, 1990), possibly due to the premature action of the secondary LH activity of PMSG. Moreover, other experimental hormonal imbalance, such as hypothyroidism or hyperprolactinemia, can cause cystic follicles in rabbits (Eyestone and $A x, 1984$ ), although the nature of the cause (or causes) remains unclear.

The ovulation rate in donor does was not significantly affected by the follicular anomalies. This suggests that antral follicles that respond to LH plus hCG, causing cystic and haemorrhagic follicles, were not a part of the preovulatory follicles destined to ovulate in normal conditions.

When ovulation is induced artificially by hCG treatment, egg transport tends to accelerate slightly (Hodgson and Pauerstein, 1976). Vicente and García-Ximénez (1991) observed that $21 \%$ of the total embryos recovered 64-66 h post-coitum were found in the uterus in hCG (25iU)-treated does. Moreover, these authors observed that premature arrival in the uterus of oviductalstage rabbit embryos resulted in a higher proportion $(37 \%)$ of morphologically abnormal embryos in the uterus than in the oviduct $(5.5 \%)$; this could be attributed to the effects of an inadequate uterine environment (Beier, 1976). For this reason, we only used embryos recovered at the ovi- 
ductal level; this explains the relatively lower embryo recovery rate obtained (74\%).

Neither embryo recovery nor morphologically normal rates were affected by donor doe strain or parity. However, follicular anomalies had a slightly negative effect on the former factor but not on the latter. This additional reduction by $7 \%$ of the oviductal embryo recovery rate could be due to an alteration of oviductal transport patterns (as well as that determined by the effect of the hCG treatment), possibly as a result of the steroidogenic capacity of cystic follicles (Hunter, 1980; Eyestone and Ax, 1984).

The negative effects of the follicular anomalies were exercised on overall transferred embryos (resulting in pregnancy failure) more than on some transferred embryos. Such negative effects on pregnancy rate were more clearly expressed by the recipients than by the donors.

In a previous work (Vicente and GarcíaXiménez, 1991), no differential negative effects of the donor doe treatment (25 IU of hCG) were observed on survival at birth of transferred fresh embryos catalogued as morphologically normal when compared with those obtained from donor does only mated with a buck. In this experiment, the embryos (fresh 64-66 h morulae) were transferred to the uterine horns of recipients that were synchronized with the donors by induction of ovulation 64$66 \mathrm{~h}$ before transfer (intravenous dose of 25 IU of hCG). However, when frozenthawed rabbit morulae (64-66 h) were transferred to hCG (25 IU)-treated recipients, the optimal synchrony was $48 \mathrm{~h}$ more than $65 \mathrm{~h}$, and the optimal transfer sites were the oviducts rather than the uterine horns (Garcia-Ximénez and Vicente, 1991). These results suggest that acceleration of oviductal egg transport, initiated by hCG induction in the ovulation treatment of recipient does, did not correspond to a diminished ability to host transferred embryos, either at $48 \mathrm{~h}$ (frozen-thawed embryos) or at 64-66 h (fresh embryos) after treatment.

The cystic follicles can secrete sexual steroids over several days (Eyestone and $A x, 1984)$, and thus also during part of the preimplantation period. In the case of recipient does, nearly all pregnancy failures occurred before the ninth or tenth day after the induction of ovulation, when pregnancy was diagnosed in transferred does by abdominal palpation. This suggests that alteration of oviductal and uterine secretion and of the transport patterns caused complete loss of the transferred embryos, during the preimplantation period, in the recipients with follicular anomalies.

In the literature we could not find any explanation for the negative effects on pregnancy rate when the donor does showed follicular anomalies; these effects were significant only when the anomalies were absent in the recipients. Such deleterious effects were not detected during morphological examination of the recovered embryos.

\section{ACKNOWLEDGMENTS}

This study was supported by CICYT Project GAN 90-0632. We wish to thank Ms Barraclough and Mr Donnellan for help with the English.

\section{REFERENCES}

Adams CE (1982) Mammalian Egg Transfer. CRC Press, Boca Raton, FL, 29-48

Beier HM (1976) Uteroglobin and related biochemical changes in the reproductive tract during early pregnancy in the rabbit. $J R e$ prod Fertil (suppl) 25, 53-69

Bomsel-Helmreich $O$, Huyen L, Vu N, DuranGasselin 1 (1989) Effects of varying doses of 
hCG on the evolution of preovulatory rabbit follicles and oocytes. Hum Reprod 4, 636-642

Bonhoff AJ, Adams CE (1985) Relationship of hormonally induced developmental changes in prevovulatory follicles of the rabbit. $L a b$ Anim 19, 27-31

Carney EW, Foote RH (1990) Effects of superovulation, embryo recovery, culture system and embryo transfer on development of rabbit embryos in vivo and in vitro. $J$ Reprod Fertil 89, 543-551

Eyestone WH, Ax RI (1984) A review of ovarian follicular cysts in cows, with comparisons to the condition in women, rats and rabbits. Theriogenology 22, 109-125

Garcia-Ximénez F, Vicente JS (1990) Effect of PMSG treatment to mating interval on the superovulatory response of primiparous rabbits. $J$ Appl Rabbit Res 13, 71-73

Garcia-Ximénez F, Vicente JS (1991) Postimplantational survival of frozen-thawed rabbit morulae relative to the site of transfer and ovulation time of recipients. $J$ App/ Rabbit Res 14 (in press)
Hodgson BJ, Pauerstein CJ (1976) Comparison of oviductal transport of fertilized and unfertilized ova after hCG or coitus-induced ovulation in rabbits. Biol Reprod 14, 377380

Hulot F, Mariana JC, Cattiau G (1988) HCGinduced ovulation in two rabbit breeds: effects of dose, season and sexual behaviour. Livest Prod Sci 20, 257-267

Hunter RHF (1980) Physiology and Technology of Reproduction in Female Domestic Animals. Academic Press, London, 65-105

Kojima T, Soma T, Oguri N (1985) Effect of rapid addition and dilution of dimethyl sufloxide on viability of frozen-thawed rabbit morulae. Cryobiology 22, 409-416

Tsunoda $Y$, Soma T, Sugie $T$ (1982) Effect of post-ovulatory age of recipient on survival of frozen-thawed rabbit morulae. J Reprod Fertil $65,483-487$

Vicente JS, García-Ximénez F (1991) Effects of hCG treatment on morula recovery in the rabbit and their survival after synchronous transfer. Anim Reprod Sci 24, 347-353 